удК 316.4

Л. Н. Батьянова

Иркутский государственный университет, г. Иркутск, Российская Федерация

С. В. Корнакова

Байкальский государственный университет, 2. Иркутск, Российская Федерация

Е. В. Чигрина

Байкальский государственный университет, 2. Иркутск, Российская Федерация

\title{
ГРАЖДАНСКИЕ ДВИЖЕНИЯ \\ КАК ВОЗМОЖНАЯ ДЕЙСТВУЮЩАЯ СИЛА СОЦИАЛЬНЫХ ПРЕОБРАЗОВАНИЙ
}

\begin{abstract}
АНнОТАЦИЯ. В данной статье авторами дан научный анализ гражданской активности, которая является одним из факторов преобразования гражданского общества. Показана значимость гражданского движения в контексте их влияния на изменение социальных условий жизни общества. Авторами рассмотрены процессы развития и функционировании таких структурных компонентов гражданского общества, как гражданские движения и инициативы, показана их значимость и влияние на изменение социальных условий жизни общества. Обобщены научные точки зрения на гражданские движения, которые обоснованно рассматриваются как неотъемлемый элемент гражданского общества, как возможная действующая сила социальных преобразований.
\end{abstract}

кЛЮчЕВЫЕ слОВА. Гражданские движения; гражданская активность; гражданское общество; государство; инициатива; государственная власть; общественные объединения.

ИНФОРМАЦИЯ О СТАТЬЕ. Дата поступления 1 марта 2017 г.; дата принятия к печати 20 марта 2017 г.; дата онлайн-размещения 31 марта 2017 г.

L. N. Batyanova Irkutsk State University, Irkutsk, Russian Federation

S. V. Kornakova Baikal State University, Irkutsk, Russian Federation

E. V. Chigrina Baikal State University, Irkutsk, Russian Federation

\section{CIVIL MOVEMENTS AS A POSSIBLE ACTIVE FORCE OF SOCIAL TRANSFORMATIONS}

ABSTRACT. The article gives a scientific analysis of the civic engagement which is one of the factors in transformation of the civil society. It shows the significance of social movements in the context of their influence on changing the social living conditions of the society. The authors consider the processes of development and functioning of such structural components of the civil society, as civil movements and initiatives; it shows their relevance and influence on changing the social conditions of the society. It summarizes scientific points of view on civil movements which are rightly viewed as an integral element of the civil society, as a potential active force for social transformations.

KEYWORDS. Civic movement; civic engagement; civil society; government; initiative; public authorities; non-governmental organizations.

ARTICLE INFO. Received March 1, 2017; accepted March 20, 2017; available online March 31, 2017.

(C) Л. Н. Батьянова, С. В. Корнакова, Е. В. Чигрина, 2017

\section{Baikal Research Journal}


В рамках теории гражданского общества интерес к изучению гражданских движений проявился с самого начала формирования данного направления. В современном российском обществе примером проявления активности граждан являются гражданские движения и инициативы, которые, к сожалению, еще не получили должного внимания исследователей. Между тем, необходимость их изучения представляется очевидной и обусловлена, прежде всего, стремительными экономическими, политическими и культурными переменами в жизни России, влекущими изменения в содержании всех социальных сфер общества.

Исследованию и научному осмыслению таких проблем, как гражданская активность в качестве фактора институционализации гражданского общества посвящены работы Р. Ф. Абдеева [1], Л. Н. Батьяновой [2], С. А. Бастриковой [3], Ф. М. Бородкина [4], В. И. Гоймана [5], Е.А. Здравомысловой [6], А. В. Одинцовой [7], С. П. Перегудова [8] и др. Указанными авторами гражданские движения обоснованно рассматриваются как неотъемлемый элемент гражданского общества, как возможная действующая сила социальных преобразований.

Сущностной характеристикой гражданских движений является их противостояние формальным бюрократическим организациям и, в первую очередь, государственным. Современный английский ученый Э. Гидденс определяет гражданское движение как «коллективную попытку осуществления общих интересов или достижение общей цели посредством коллективного действия вне рамок установленных институтов» [9, с. 583]. Из данного определения следует, что гражданские движения, являясь современной формой самоорганизации гражданского общества, в первую очередь, имеют своей целью изменение условий существования больших социальных групп посредством изменения формальных процедур принятия государственных решений.

Следующей существенной чертой гражданских движений выступает их целевая направленность, которая базируется на определенной системе ценностей. Следует иметь в виду, что новая ценностная система может оказывать существенное влияние на законодательную практику государства и в подобных случаях «гражданские движения могут превращаться в формальные организации» [9, с. 483]. Такими формальными организациями, в частности, выступают различного рода консультативные группы при государственных органах, политические партии, ассоциации, научные и исследовательские учреждения, центры и фонды. Как правило, наличие подобной формализации деятельности гражданских движений означает определенное достижение поставленных целей, поскольку в процедуру принятия государственных решений внедрена разработанная гражданскими движениями система ценностей.

Критериями выделения гражданских движений из всей совокупности проявления гражданской активности являются:

- противостояние формальным бюрократическим организациям;

- процедуры принятия решений;

- массовость;

- существование собственной системы ценностей и целей, отражающих интересы конкретных социальных групп.

По приведенным параметрам гражданские движения явно контрастируют с группами интересов, целью создания которых является оказание давления на политиков [10, с. 137].

Кроме этого, наиболее распространенной формой относительной самостоятельности и активности гражданского общества выступают его гражданские инициативы, под которыми принято понимать способ существования и развития субъектов общественной жизни, основанном на стремлении к изменению социальных

\section{Baikal Research Journal}


условий и формированию собственных качеств (интересов, способностей, ценностей, установок, намерений, ориентаций).

Основной предпосылкой сознательной гражданской инициативы является осознанный и свободный выбор носителя инициативы вариантов (возможностей) своего участия в жизни общества. Каждый конкретный носитель инициативы, прежде всего, определяет характер своего участия в жизни общества, степень или меру интенсивности своей деятельности, и лишь затем занимает определенную социальную позицию.

Характерной чертой гражданских инициатив выступает также деятельное познавательное и практическое отношение личности, группы, организации и т. д. к делам общества, условиям жизнедеятельности, которое может проявляться не только в форме созидательной, творческой, т. е. общественно-полезной деятельности, но и в форме асоциальной деятельности, отклоняющегося от нормы (девиантного) поведения. Гражданские инициативы характеризуются высокой степенью динамичности и способностью к преобразованиям. Именно готовность и способность людей к переменам, по мнению М. Вебера, являются предопределяющими в трансформационных процессах любой экономической системы [11]. В связи с этим гражданскую инициативу в контексте гражданского общества можно определить, как форму активности, благодаря которой разрабатывается и реализуется та или иная стратегия гражданского участия в различных сферах общественной жизни. Следует подчеркнуть, что понятие «стратегия» относится к сознательным проявлениям как физического, так и юридического лица, выступающего в качестве носителя (субъекта) активности, поведения и деятельности.

Стратегии гражданского участия - не единственный способ специфического отражения образа воли людей к жизни, их стремлений к самоорганизации собственной жизни и жизни ближайшего окружения. Наряду с ними на развитие гражданина влияют и способы реализации жизнедеятельности (образ, стиль жизни, ее уклад), способы определения гражданских ситуаций (линия поведения и гражданская позиция), способы описания жизни (жизненная история, биография) и способы символического конструирования жизни (жизненные перспективы, сценарии, планы,).

Определением, наиболее полно выражающим социальную специфику гражданских стратегий, является следующее. Гражданская стратегия - это динамическая система перспективного ориентирования носителя активности, направленная на сознательное изменение своей будущей жизни в данном социокультурном контексте. Такая система ориентирования направляет и регулирует поведение носителя активности в течение продолжительного времени.

Одной из значимых особенностей, характеризующих гражданскую инициативность выступает субъектность личности, наличие которой свидетельствует об изменении не отдельных сторон носителя инициативы, а всего его образа жизни.

Если под субъектностью вообще понимается способность индивида быть автором и хозяином своей активности $[12$, с. 44], то в данном случае субъектность предполагает устойчивую способность личности, направленную на изменение и преобразование общественных условий жизни в соответствии с его убеждениями, взглядами, ценностными установками. С точки зрения общественной значимости, субъектность носителя может быть как позитивной, конструктивной (созидательной), адекватной общественным нормам и идеалам, так и негативной, деструктивной (разрушительной), ориентированной на подрыв существующих в обществе устоев, традиций и правил общежития. Однако критерий правильности субъектности лежит не только в общественном признании, одобрении и поддержке, порождающими иногда настроение соглашательства (конформизма) и равно-

\section{Baikal Research Journal}

электронный научный журнал Байкальского государственного университета 
душия (апатии). Гораздо более важным для понимания субъектности является требование соблюдения автономии - автономных прав и гражданских свобод личности. Субъектность становится в гражданском обществе необходимым элементом жизнедеятельности автономных субъектов. Она выражает их способность к расширению и укреплению своего жизненного пространства, рассматриваемого в контексте самореализации личности (группы) и свободного творчества.

Следует добавить, что возникновение гражданских движений и проявление инициатив обычно имеет место на основе экономических и культурных изменений, которые могут представлять в некоторые периоды значительную силу, изменяющую общество. Другими словами, бурное развитие гражданских движений это верный признак переходного состояния общества [13, с. 77]. Это обусловлено тем, что в такие исторические периоды в обществе нарастает ощущение беспокойства, напряженности, появляется элемент неудовлетворенности каких-либо потребностей среди широких групп населения, в результате чего инициируется смысловое переопределение социальной реальности, в ходе которого носители новых смысловых комплексов и формируют социальные движения и инициативы.

В этой связи не случайно и показательно то обстоятельство, что начало становления гражданских движений в России приходится на конец 80-х гг., когда в нашем обществе возникли и начали оформляться основные «темы протеста» граждан. Политические реформы в перестроечный период способствовали возникновению возможности для появления инициативных форм политического участия в виде коллективных действий и организаций, получивших называние неформальных, или гражданских движений. Сам факт наличия конфронтации с властными структурами гражданских движений определил начало для обсуждения данной проблематики в общественной и профессиональной дискуссии, причем на конфликтный потенциал такой формы гражданской активности как гражданские движения указывают как отечественные, так и зарубежные исследователи $[14 ; 15]$. Публичный и профессиональный интерес к этой проблеме появился и развивается параллельно с появлением и развитием гражданских движений.

Первичное описание и анализ гражданских движений и инициатив становятся, в первую очередь, частью публичного официального (в официальных СМИ) и неофициального обсуждения (в «самиздате» и полулегальной прессе). При этом первым недифференцированным обозначением гражданских движений в средствах массовой информации стал термин «неформалы». Он подразумевал три аспекта: во-первых, инициативные организации, во-вторых, организованные ими коллективные действия и, в-третьих, их участников. Появившимся и прочно укрепившемся в общественном сознании и обиходе термином «неформалы», подчеркивалось их коренное отличие от институциональных структур советского общества, поскольку они имели инициативный, нерегламентированный и не «заданный сверху» характер. Позднее этот термин ушел из научных дискуссий. Исследователями того периода гражданские движения определялись как имеющая конфликтный характер и определенную степень стабильности инициативная коллективная деятельность, направленная на преобразование социальной действительности [16, с. 32]. В качестве основных характеристик исследователями отмечались:

- коллективный характер;

- активная преобразовательная деятельность;

- наличие организации;

- общность интересов;

- мобилизационная активность;

- наличие конфронтации.

\section{Baikal Research Journal}

электронный научный журнал Байкальского государственного университета 
Выделялись три компонента гражданских движений - протестные действия, коллективная идентичность, организация. Особенно подчеркивалась «субъектность» движений, т. е. их деятельностное и коллективное начало [16, с. 32-33].

Постепенно в научный оборот исследователей гражданских движений вошли такие понятия, как «коллективное действие», «протест», «мобилизация», «ресурсы», "репертуар протеста», «структура политических возможностей», «цена участия» и пр. Этим понятиям даются определения, они операционализируются [17]. Так формировался язык описания, общий для исследований в этой области.

Для изучения протеста как формы гражданской активности необходимо исследование акций и контингента граждан, участвующих в таких акциях. Протест при этом определяется как социальное поведение субъектов, которые представляют интересы организаций, социальных групп или общества в целом, направленное против государственных институтов или других социальных субъектов [18, с. 23-34]. К примеру, рабочие движения используют форму протеста для достижения экономических и политических целей, где под рабочим движением понимается движение, выражающее интересы всех наемных работников, противостоящие интересам ведомственного и хозяйственно-политического аппарата [19, с. 232].

При исследовании причин возникновения рабочих движений, динамики их взаимодействия (между собой, с властью, с другими движениями) на локальном, региональном и национальном уровнях можно выделить два направления «организационного строительства" в рамках самих рабочих движений: создание новых структур (рабочих клубов, профсоюзов, объединений и ассоциаций, рабочих и забастовочных комитетов) и преобразование старых профсоюзов.

Среди гражданских движений выделяется экологическое движение, как один из типов социальной организации гражданского общества. Само понятие «экологическое движение» охватывает целый ряд событий, действий и процессов, в которых оно развивается. В отличие от других движений, экологические движения возникают уже в период «хрущевской оттепели», что в немалой степени объясняется их минимальной политизированностью. Различие между экологическим движением $60-\mathrm{x}-70-\mathrm{x}$ гг. и движением 80-90 х гг. заключается в том, что если ранее они выполняли заказы органов государственной власти, то позднее «зеленые» стали ее оппонентами.

Следует учитывать, что установка на заинтересованное гражданское участие является неотъемлемым компонентом демократической политической культуры. Именно посредством гражданских движений его участники делают правительство ответственным перед волей народа. Более того, хорошо известно, что в более развитом гражданском обществе более его социальная структура. Следовательно, чем более развита система общественных структур, тем полнее проявляется многообразие интересов различных социальных слоев населения, а значит возможность их учета при выработке политического курса страны.

Тем не менее, количественный бум возникновения и проявления всевозможных гражданских движений и инициатив не всегда отвечает потребностям общественного развития, ибо за количественной стороной данного, во многом положительного, процесса подчас не видно качественной составляющей. Участие граждан, даже активное, в деятельности различных общественных структур само по себе автоматически не влечет за собой проявления инициативности и активности в постановке и решении вопросов, которые имеют значение для общества или государства. Надо вести целенаправленную работу по формированию гражданской активности личности [20, с. 100]. Поэтому воспитательная функция, функция социализации личности - одна из важнейших в деятельности многочисленных гражданских движений.

\section{Baikal Research Journal}

электронный научный журнал Байкальского государственного университета 
В гражданском обществе общественным объединениям принадлежит не только функция выражения интересов определенных социальных слоев, отдельных национальностей (создаваемые по национальному признаку народные фронты, ассоциации), а также личностных интересов, Кроме этого, необходим существенный рост ответственности гражданских движений перед обществом, а также общественных организаций и объединений перед своими членами [20, с. 126].

Обобщение научных точек зрения на условия возникновения, функционирования и развития гражданских движений и инициатив показало, что гражданская активность возрастает при наличии в обществе конфликтов [21]. Тем не менее, возможен социальный контроль со стороны государственной власти за активизацией гражданских движений, осуществляемый посредством включения переговорных процессов, что зачастую влечет за собой сближение конфликтных позиций. Поэтому государственная политика в отношении гражданских движений должна быть построена таким образом, чтобы имелась возможность адаптации инновационного потенциала гражданских инициатив к практике принятия государственных решений и минимизации негативных последствий неконтролируемой гражданской активности. Кроме этого, деятельность гражданских движений и инициатив, направленная на формирование гражданского общества, может иметь успех только в том случае, когда она адекватна по своим сущностным признакам типу общества.

В России в настоящее время еще не сложилась совершенная законодательная база, не накоплен достаточный опыт общения власти с представителями различных гражданских движений и инициатив. Тем не менее, уже существует определенный задел формирующейся гражданской активности граждан, направленностью которого должно быть преодоление рамок исключительно «тем протеста» и увеличение ответственных, инициативных и рефлексивных участников социального творчества.

\section{Список использованной литературы}

1. Абдеев Р. Ф. Философия информационной цивилизации / Р. Ф. Абдеев. - М. : Гуманит. изд. центр «ВЛАДОС», 1994. - 334 с.

2. Батьянова Л. Н. Гражданское общество в современной России: особенности институционализации и функционирования : автореф. дис. ... канд. фил. наук : 09.00.11/ Л. Н. Батьянова. - Иркутск, 2009. - 22 с.

3. Бастрикова С. А. Интернет в системе взаимодействия государства и формирующегося гражданского общества Российской Федерации : дис. ... канд. политол. наук : 23.00.03 / С. А. Бастрикова. - М., 2000. - 165 с.

4. Бородкин Ф. М. Общественные движения как элемент самоуправления (Опыт СССР) / Ф. М. Бородкин. - Новосибирск : Наука, 1990. - 245 с.

5. Гойман В. И. Формирование правовой активности личности : монография / В. И. Гойман. - М. : Высш. шк., 1988. - 196 с.

6. Здравомыслова Е. А. Парадигмы западной социологии общественных движений / Е. А. Здравомыслова. - СПб. : Наука, 1993. - 456 с.

7. Одинцова А. В. Современные проблемы развития гражданского общества / А. В. Одинцова. - М. : Ин-т экономики АН СССР, 1989. - 193 с.

8. Перегудов С. П. Гражданское общество как политический феномен / С. П. Перегудов // Свободная мысль. - 1992. - № 9. - С.43-53.

9. Гидденс Э. Социология / Э. Гидденс. - М. : Эдиториал УРСС, 1999. - 703 с.

10. Батьянова Л. Н. Гражданское общество в современной России: особенности институционализации и функционирования : дис. ... канд. фил. наук : 09.00.11 / Л. Н. Батьянова. - Иркутск, 2009. - 157 с.

11. McClelland D. C. The Achieving Socitty / D. C. McClelland. - New York : The Free Press, 2011. - $530 \mathrm{p}$.

\section{Baikal Research Journal}

электронный научный журнал Байкальского государственного университета 
12. Алексеева Л. В. Юридическая психология : учеб.-метод. комплекс / Л. В. Алексеева. - Тюмень : Изд-во Тюм. гос. ун-та, 2001. - 240 с.

13. Баялджиев Д. Идея правового государства и функционирования государства в условиях переходного периода / Д. Баялджиев // Вестник Московского университета. Сер. 11, Право. - 1998. - № 6. - С. 76-92.

14. Нагайчук А. Ф. Конфликт интересов в сфере социальной политики / А. Ф. Нагайчук // Социологические исследования. - 2006. - № 3. - С. 48-53.

15. Domrin A. N. Ten Years Later: Society, "Civil Society», and the Russian State / A. N. Domrin // Russian Review. - 2003. - № 62. - P. 193-211.

16. Интеллигенция и проблемы формирования гражданского общества в России : тез. докл. Всерос. конф., 14-15 апр. 2000 г. / отв. ред. М. И. Кондрашова. - Екатеринбург : Урал. гос. ун-т, 2000. - 264 с.

17. Перегудов С. П. Группы интересов и российское государство / С. П. Перегудов, Н. Ю. Лапина, И. С. Семененко. - М. : Эдиториал УРСС, 1999. - 352 с.

18. Резник Ю. М. Человек и общество (опыт комплексного изучения) / Ю. М. Резник // Личность. Культура. Общество. - 2000. - Т. 2, вып. 4 (6). - С. 23-34.

19. Гражданское общество в России: структура и сознание / под ред. К. Холодковского. - М. : Наука, 1998. - 252 с.

20. Корнакова С. В. Правовая культура личности как условие эффективной реализации ее прав и свобод / С. В. Корнакова, Е. В. Чигрина // 20 лет Конституции России: актуальные проблемы развития правового государства : сб. науч. тр. / редкол: В. Н. Андриянов, Н. В. Кешикова, В. П. Моисеев [и др.]. - Иркутск : Изд-во БГУЭП, 2014. - С. 125-136.

21. Гражданское участие: Ответственность. Сообщество. Власть : неконцептуальный сборник / отв. ред. Р. Г. Апресян. - М. : Аслан, 1997. - 111 с.

\section{References}

1. Abdeyev R. F. Filosofiya informatsionnoi tsivilizatsii [Philosophy of Information Civilization]. Moscow, VLADOS Publ., 1994. 334 p.

2. Batyanova L. N. Grazhdanskoe obshchestvo $v$ sovremennoi Rossii: osobennosti institutsionalizatsii $i$ funktsionirovaniya. Avtoref. Kand. Diss. [Civil society in modern Russia: features of institutionalization and functioning. Cand. Diss. Thesis]. Irkutsk, 2009. $22 \mathrm{p}$.

3. Bastrikova S. A. Internet $v$ sisteme vzaimodeistviya gosudarstva i formiruyushchegosya grazhdanskogo obshchestva Rossiiskoi Federatsii. Kand. Diss. [The Internet in the system of interaction of state and forming civil society in the Russian Federation. Cand. Diss.]. Moscow, 2000. $165 \mathrm{p}$.

4. Borodkin F. M. Obshchestvennye dvizheniya kak element samoupravleniya (Opyt SSSR) [Public movements as an element of self-governance (experience of the USSR)]. Novosibirsk, Nauka Publ., 1990. 245 p.

5. Goiman V. I. Formirovanie pravovoi aktivnosti lichnosti [Formation of personal legal activity]. Moscow, Vysshaya shkola Publ., 1988. 196 p.

6. Zdravomyslova E. A. Paradigmy zapadnoi sotsiologii obshchestvennykh dvizhenii [Paradigms of western sociology of public movements]. Saint Petersburg, Nauka Publ., 1993. 456 p.

7. Odintsova A. V. Sovremennye problemy razvitiya grazhdanskogo obshchestva [Modern problems of developing civil society]. Moscow, Institute of Economic of Academy of Sciences of the USSR Publ., 1989. $193 \mathrm{p}$.

8. Peregudov S. P. Civil society as a political phenomenon. Svobodnaya mys = Free Thought, 1992, no. 9, pp. 43-53. (In Russian).

9. Giddens E. Sotsiologiya [Sociology]. Moscow, Editorial URSS Publ., 1999. 703 p.

10. Batyanova L. N. Grazhdanskoe obshchestvo $v$ sovremennoi Rossii: osobennosti institutsionalizatsii i funktsionirovaniya. Kand. Diss. [Civil society in modern Russia: features of institutionalization and functioning. Cand. Diss.]. Irkutsk, 2009. 157 p.

11. McClelland D. C. The Achieving Society. New York, The Free Press, 2011. 530 p.

12. Alekseyeva L. V. Yuridicheskaya psikhologiya [Juridical Psychology]. Tyumen State University Publ., 2001. 240 p.

13. Bayaldzhiev D. Idea of the legal state and functioning of the legal state in terms of transitional period. Vestnik Moskovskogo universiteta. Seriya 11, Pravo = Moscow University Bulletin. Series 11, Law, 1998, no. 6, pp. 76-92. (In Russian).

\section{Baikal Research Journal}


14. Nagaichuk A. F. Conflict of interests in the sphere of social policy. Sotsiologicheskie issledovaniya $=$ Sociological Studies, 2006, no. 3, pp. 48-53. (In Russian).

15. Domrin A. N. Ten years later: society, «civil society», and the Russian state. Russian Review, 2003, no. 62, pp. 193-211.

16. Kondrashova M. I (ed.). Intelligentsiya i problemy formirovaniya grazhdanskogo obshchestva $v$ Rossii. Materialy Vserossiiskoi konferentsii, 14-15 aprelya $2000 \mathrm{~g}$. [The intellectuals and problems of forming civil society in Russia. Materials of All-Russian Conference, April 14-15, 2000]. Yekaterinburg, Ural State University of Economics Publ., 2000. 264 p.

17. Peregudov S. P., Lapina N. Yu., Semenenko I. S. Gruppy interesov i rossiiskoe gosu darstvo [Groups of interests and Russian state]. Moscow, Editorial URSS Publ., 1999. 352 p.

18. Reznik Yu. M. Man and society (experience of complex studies). Lichnost'. Kul'tura. Obshchestvo = Person. Culture. Society, 2000, vol. 2, iss. 4 (6), pp. 23-34. (In Russian).

19. Kholodkovsky K. (ed.). Grazhdanskoe obshchestvo v Rossii: struktura i soznanie [Civil society in Russia: structure and consciousness]. Moscow, Nauka Pub., 1998. 252 p.

20. Kornakova S. V., Chigrina E. V. Personal legal culture as a condition of effective implementation of his/her rights and freedoms. In Andriyanov V. N., Keshikova N. V., Moiseyev V. P. (eds). 20 let Konstitutsii Rossii: aktual'nye problemy razvitiya pravovogo [20 years of the Constitution of Russia: Topical Problems of Developing a Legal State]. Irkutsk, Baikal State University Economics and Law Publ., 2014, pp. 125-136. (In Russian).

21. Apresyan R. G. (ed.). Grazhdanskoe uchastie: Otvetstvennost'. Soobshchestvo. Vlast' : nekontseptual'nyi sbornik [Civil participation: Responsibility. Community. Power: non-conceptual collection]. Moscow, Aslan Publ., 1997. 111 p.

\section{Информация об авторах}

Батьянова Людлила Николаевна - кандидат философских наук, доцент, кафедра государственного и муниципального управления, Иркутский государственный университет, 664003, г. Иркутск, ул. Ленина, 3; e-mail: chigrinaev@bgu.ru.

Корнакова Светлана Викторовна - кандидат юридических наук, доцент, кафедра уголовного права, уголовного процесса и криминологии. Байкальский государственный университет, 664003, г. Иркутск, ул. Ленина, 11; e-mail: Svetlana-kornakova@yandex.ru.

Чигрина Елена Владимировна - кандидат экономических наук, доцент, кафедра теории государства и права и социально-правовых дисциплин. Байкальский государственный университет, 664003, г. Иркутск, ул. Ленина, 11; e-mail: chigrinaev@bgu.ru.

\section{Authors}

Lyudmila N. Batianova - PhD in Philosophy, Associate Professor, Chair of Public Administration and Municipal Management, Irkutsk State University, 3 Lenin St., 664003, Irkutsk, Russian Federation; e-mail: chigrinaev@bgu.ru.

Svetlana V. Kornakova - PhD in Law, Associate Professor, Chair of Criminal Law, Criminal Procedure and Criminology, 11 Lenin St., Baikal State University, 664003, Irkutsk, Russian Federation; e-mail: Svetlana-kornakova@yandex.ru.

Elena V. Chigrina - PhD in Economics, Associate Professor, Chair of Theory of State and Law and Socio-Legal Disciplines, Baikal State University, 11 Lenin St., 664003, Irkutsk, Russian Federation; e-mail: chigrinaev@bgu.ru.

\section{Библиографическое описание статьи}

Батьянова Л. Н. Гражданские движения как возможная действующая сила социальных преобразований / Л. Н. Батьянова, С. В. Корнакова, Е. В. Чигрина // Baikal Research Journal. - 2017. — T. 8, № 1. - DOI: 10.17150/2411-6262.2017.8(1).23.

\section{Reference to article}

Batyanova L. N., Kornakova S. V., Chigrina E. V. Civil movements as a possible active force of social transformations. Baikal Research Journal, 2017, vol. 8, no. 1. DOI: 10.17150/24116262.2017.8(1).23. (In Russian).

\section{Baikal Research Journal}

